\title{
ANALISIS FAKTOR YANG MEMENGARUHI KECELAKAAN KERJA PADA PENGOPERASIAN CONTAINER CRANE DI PT X SURABAYA TAHUN 2013-2015
}

\author{
Lilian Enggal Ekasari \\ PT Sarana Duta Mandiri \\ Perumahan Wisma Sarinadi Blok. S No. 13 Sidoarjo \\ Email: lilianenggal@gmail.com
}

\begin{abstract}
Container crane for loading and unloading activities has accident hazard. It will induce accidents that result in economic and non-economic losses if not controlled. Therefore, this study aim to identify accidents in the operation of the container crane and factors that influence during the years 2013-2015.This research is observational research by describing the variables objectively. The data source of this research are reported of accidents in 2013-2015 and interviews related factors that affect accidents. The results showed that the number of accidents in the operation of the container crane continues to increase in a row from 2013-2015 year, that is 94, 69, 71. The value of average statistical that includes FR, $S R$ and IR is 476.82, 0 and 110, 33. That value is high, although figures obtained SR is 0. For factors that influence the occurrence of accidents is unsafe worker behavior, supervision systems, implementation of work instructions, maintenance and operation of the container crane related some programs that dysfunction. Based on the results of this study concluded that the incidence and frequency of accidents is high although severity rate is 0 . Causes of accidents are supervision system, implementation of work instruction unfavorable and dysfunction some programs related the operation of the container crane. Implementation of the program should be made to reduce the number of accidents in the operation of the container crane.
\end{abstract}

Keywords: accident, crane, port

\begin{abstract}
ABSTRAK
Pengoperasian container crane untuk kegiatan bongkar muat memiliki potensi kecelakaan kerja. Potensi bahaya tersebut jika tidak dikendalikan maka akan menyebabkan kecelakaan kerja yang berakibat pada kerugian ekonomi maupun non ekonomi. Tujuan dari penelitian ini adalah untuk mengidentifikasi kejadian kecelakaan kerja pada pengoperasian container crane serta faktor yang mempengaruhinya selama tahun 2013-2015. Penelitian ini bersifat penelitian observasional dengan menggambarkan variabel yang diteliti secara obyektif. Sumber data penelitian ini adalah laporan kecelakaan kerja tahun 2013-2015 dan wawancara terkait faktor yang mempengaruhi kecelakaan kerja. Hasil penelitian menunjukkan bahwa angka kecelakaan pada pengoperasian container crane masih terus mengalami peningkatan secara berturut-turut dari tahun 20132015 yaitu 94, 69, 71. Rata-rata nilai statistik yang meliputi FR, SR dan IR yaitu 476,82, 0 dan 110,33. Angka tersebut tergolong tinggi meskipun angka SR yang didapat adalah 0 . Untuk faktor yang mempengaruhi terjadinya kecelakaan adalah perilaku tidak aman pekerja, sistem pengawasan, implementasi instruksi kerja, maintenance dan beberapa program terkait pengoperasian container crane yang tidak berjalan. Berdasarkan hasil penelitian dapat disimpulkan bahwa insiden dan frekuensi kecelakaan kerja tinggi meskipun tingkat keparahannya 0 . Hal ini dikarenakan sistem pengawasan, implementasi instruksi kerja yang kurang baik serta tidak berjalannya beberapa program terkait pengoperasian container crane. Pelaksanaan program terkait pengoperasian container crane hendaknya dilakukan untuk mengurangi angka kecelakaan kerja pada pengoperasian container crane.
\end{abstract}

Kata kunci: kecelakaan kerja, crane, terminal petikemas

\section{PENDAHULUAN}

Kegiatan bongkar muat petikemas adalah salah satu kegiatan di pelabuhan dan merupakan kegiatan inti dalam transportasi muatan. Kegiatan ini memerlukan alat bantu yang digunakan untuk mempercepat pekerjaan seperti container crane, rubber tyred gantry crane (RTG) dan truck (Trivitas, 2016).

Pengoperasian alat bantu bongkar muat memiliki potensi bahaya seperti terjatuh, tertimpah, tertumbuk atau terjepit. Potensi bahaya yang menyertai pengoperasian fasilitas bongkar muat ini jika tidak dikendalikan atau dilakukan pencegahan 
maka akan menyebabkan kecelakaan kerja dan berakibat pada kerugian ekonomi maupun non ekonomi (Anizar, 2009).

Menurut data Maritime Department of Hongkong dalam Fhadilla (2016) kecelakaan pada kegiatan bongkar muat petikemas di Hongkong masih tinggi dan masih cenderung meningkat dari tahun 2010 sampai 2012. Tahun 2010 terjadi 167 kasus kecelakaan kerja dan meningkat pada tahun 2011 menjadi 215 kasus. Pada tahun 2012 terjadi penurunan angka kecelakaan pada kegiatan bongkar muat petikemas namun angka kejadiannya masih tinggi yaitu sekitar 126 kasus. Kejadian tersebut harus dilakukan pencegahan agar tidak terjadi kerugian.

Definisi kecelakaan kerja adalah suatu kejadian tidak diduga dan tidak dikehendaki yang mengacaukan proses suatu aktivitas yang telah diatur. Pencegahan kecelakaan kerja bisa dilakukan dengan melihat hierarki pengendalian. Hierarki pengendalian kecelakaan kerja adalah eliminasi, substitusi, rekayasa teknik, administrasi dan yang terakhir adalah dengan penggunaan alat pelindung diri (APD).

Sebelum melakukan pengendalian kecelakaan kerja harusnya dilakukan analisis mengenai kecelakaan kerja yang terjadi serta faktor yang mempengaruhi agar kecelakaan serupa tidak terulang (Anizar, 2009). Analisis penyebab kecelakaan kerja bisa dilakukan dengan menerapkan teori kecelakaan kerja seperti teori International Loss Control Institute (ILCI) Loss Causation Model oleh Bird dan Gemain (1992) dalam McKinnon (2000). Teori ini mengacu pada urutan peristiwa penyebab kecelakaan kerja yang mengakibatkan kerugian dan teori ini dapat menganalisis kecelakaan kerja yang terjadi sampai pada tingkat manajemen. Teori ini menyebutkan bahwa kecelakaan kerja mempunyai dampak kerugian (loss) dan timbul akibat kecelakaan yang terjadi sebelumnya. Sedangkan kecelakaan itu sendiri dapat disebabkan oleh beberapa faktor antara lain penyebab langsung (immediate causes), penyebab dasar (basic causes), dan kurangnya pengawasan (lack of control).

PT X Surabaya merupakan perusahaan yang bergerak di bidang pelayanan dan penyediaan jasa fasilitas terminal petikemas baik perdagangan domestik maupun internasional. Data kecelakaan kerja tahun 2013 di PT X Surabaya sebanyak 206 kasus dan terjadi pada operator mobile equipment.
Dari 206 kasus tersebut, sebagian besar terjadi pada operator container crane yaitu sebanyak 94 kasus.

Berdasarkan dari tingginya angka kecelakaan pada pengoperasian container crane maka perlu dilakukan identifikasi kecelakaan serta faktor yang mempengaruhi terjadinya kecelakaan kerja pada pengoperasian container crane agar dapat dilakukan pengendalian atau pencegahan yang tepat sehingga kejadian yang sama tidak terulang. Tujuan penelitian ini adalah untuk mengidentifikasi kejadian kecelakaan kerja pada pengoperasian container crane dan faktor yang memengaruhinya di PT X Surabaya Tahun 2013-2015.

\section{METODE}

Penelitian ini termasuk penelitian observasional, dari segi waktu penelitian ini bersifat case study karena akibat telah ada dahulu kemudian dicari penyebabnya dan berdasarkan cara analisis datanya penelitian ini merupakan penelitian deskriptif.

Populasi pada penelitian ini adalah semua pekerja yang terlibat saat pengoperasian container crane yaitu operator container crane, Safety Supervisor, Berth Operation Superintendent dan Operator Superintendent. Besar sampel yang diteliti adalah 4 orang operator yang pernah mengalami kecelakaan saat pengoperasian container crane, 1 orang Safety Supervisor, 1 orang Berth Operation Superintendent dan 1 orang operator Superintendent di PT X Surabaya sebagai sumber informasi penelitian. Cara pengambilan sampel yaitu menggunakan teknik purposive sampling dengan kriteria sampel yaitu pekerja yang terlibat saat kecelakaan kerja terjadi.

Penelitian ini dilakukan di PT X Surabaya yang beralamat di Jalan Tanjung Mutiara No 1 Surabaya. Penelitian dimulai sejak pembuatan proposal pada bulan Maret 2016. Pengambilan data dilakukan pada bulan Oktober 2016. Pengolahan data dilakukan pada bulan Oktober-November 2016.

Variabel penelitian ini adalah kecelakaan kerja meliputi frequency rate, severity rate, incidence rate, serta faktor yang mempengaruhi kecelakaan meliputi faktor immediate cause, faktor basic cause, dan faktor lack of control. Cara pengumpulan data yaitu dengan melakukan wawancara dan pengumpulan data sekunder kemudian data diolah dengan tabulasi silang dan disajikan dalam bentuk tabel agar mudah dalam pemahamannya. 
Tabel 1. Jumlah Kecelakaan Kerja pada Pengoperasian Container Crane di PT X Surabaya Tahun 2013-2015

\begin{tabular}{ccc}
\hline \multirow{2}{*}{ Tahun } & \multicolumn{2}{c}{ Jumlah Kecelakaan Kerja } \\
\cline { 2 - 3 } & $\mathbf{n}$ & $\mathbf{\%}$ \\
\hline 2013 & 94 & 40,17 \\
2014 & 69 & 29,49 \\
2015 & 71 & 30,34 \\
\hline Jumlah & 234 & $100 \%$ \\
\hline
\end{tabular}

Tabel 2. Identifikasi Statistik Angka Kecelakaan Kerja pada Pengoperasian Container Crane di PT X Surabaya

\begin{tabular}{lccc}
\hline \multirow{2}{*}{ Tahun } & \multicolumn{3}{c}{ Statistik Kecelakaan Kerja } \\
\cline { 2 - 4 } & FR & SR & IR \\
\hline 2013 & 574,63 & 0 & 132,39 \\
2014 & 421,80 & 0 & 97,18 \\
2015 & 434,03 & 0 & 101,41 \\
\hline Rata-rata & 476,82 & 0 & 110,33 \\
\hline
\end{tabular}

\section{HASIL}

Identifikasi Angka Kecelakaan Kerja pada Pengoperasian Container Crane Tahun 2013-2015 di PT X Surabaya

Pengoperasian container crane adalah pekerjaan yang dilakukan untuk membantu proses bongkar muat petikemas di PT X Surabaya. Tingginya arus bongkar muat yang terjadi setiap harinya akan sangat berpengaruh pada risiko kecelakaan yang menyertai pengoperasian container crane. Berikut adalah angka kejadian kecelakaan PT X Surabaya Tahun 2013-2015.

Identifikasi Statistik Kecelakaan Kerja pada Pengoperasian Container Crane (Frequency Rate, Severity Rate dan Incidence Rate) di PT X Surabaya Tahun 2013-2015

Distribusi angka kecelakaan yang meliputi frequency rate, severity rate dan incidence rate pada pengoperasian container crane perlu diidentifikasi untuk menilai kejadian kecelakaan yang terjadi pada pengoperasian container crane. Penilaian tersebut dilakukan untuk menilai frekuensi kejadian kecelakaan kerja, keparahan dari kecelakaan kerja dan besarnya kejadian pada operator container crane. Berikut adalah angka statistik kejadian kecelakaan pada pengoperasian container crane pada Tahun 2013-2015 yaitu:
Tabel 3. Identifikasi Faktor Immediate Cause yang Mempengaruhi Terjadinya Kecelakaan pada Pengoperasian Container Crane di PT X Surabaya Tahun 2013-2015

\begin{tabular}{ccccc}
\hline \multirow{2}{*}{ Tahun } & \multicolumn{4}{c}{ Immediate Cause } \\
\cline { 2 - 5 } & Unsafe Action & \multicolumn{1}{c}{ Unsafe Condition } \\
\cline { 2 - 5 } & $\mathbf{n}$ & \% & n & \% \\
\hline 2013 & 64 & 27,35 & 30 & 12,82 \\
2014 & 50 & 21,37 & 19 & 8,12 \\
2015 & 64 & 27,35 & 7 & 2,99 \\
\hline Jumlah & 178 & 76,07 & 56 & 23.93 \\
\hline
\end{tabular}

Dari angka kecelakaan kerja di PT X Surabaya Tahun 2013-2015 didapatkan angka statistik kecelakaan kerja yang nilai Frequency Rate (FR), Severity Rate (SR) dan Incidence Rate (IR). Rata-rata nilai Frequency Rate (FR) pada tahun 2013-2015 adalah 476,82.

Angka FR yang didapat pada tahun 2013-2015 tersebut akhirnya akan berpengaruh pada angka severity rate (SR). Severity Rate (SR) pada pengoperasian container crane pada 2013-2015 adalah 0 , hal ini disebabkan juga karena kejadian kecelakaan pada pengoperasian container crane tidak sampai berakibat Lost Time Injuries (LTI) yaitu kecelakaan kerja yang tidak sampai menimbulkan jam kerja hilang lebih dari $2 \times 24$ jam.

Angka statistik terakhir yaitu angka tingkat kejadian kecelakaan kerja pada pengoperasian container crane. Angka kejadian bisa terlihat dari angka incidence rate yang menggambarkan angka kejadian per seratus tenaga kerja terpapar. Dari perhitungan hasil incidence rate pada Tahun 2013-2015 didapatkan hasil rata-rata yaitu 110 kejadian kecelakaan per seratus tenaga kerja terpapar.

Identifikasi Faktor Immediate Cause yang Mempengaruhi Terjadinya Kecelakaan pada Pengoperasian Container Crane di PT X Surabaya Tahun 2013-2015

Penyebab langsung dari suatu kecelakaan adalah tindakan tidak aman dari operator container crane dan kondisi tidak aman area kerja. Kondisi tidak aman disini bisa kondisi dari alat kerjanya sendiri yaitu container crane atau kondisi kapal saat kegiatan bongkar muat, sedangkan untuk tindakan tidak aman disini adalah tindakan dari operator container crane itu sendiri yang mengakibatkan 
kecelakaan. Keadaan seperti itulah yang nantinya akan mempengaruhi terjadinya kecelakaan kerja. Sejauh ini penyumbang kecelakaan paling sering disebabkan oleh perilaku tidak aman dari pekerja. $\mathrm{Hal}$ ini dikarenakan sifat ceroboh dan ingin cepat selesai dalam melakukan pekerjaan. Berikut adalah faktor immediate cause yang mempengaruhi kecelakaan kerja:

\section{Identifikasi Faktor Basic Cause yang Mempengaruhi Terjadinya Kecelakaan Kerja pada Pengoperasian Container Crane di PT X Surabaya Tahun 2013-2015}

Faktor selanjutnya yang mempengaruhi terjadi kecelakaan kerja adalah faktor penyebab dasar atau basic cause. Basic cause yang mempengaruhi kecelakaan disini pengawasan, maintenance alat dan instruksi kerja.

\section{Pengawasan}

Pengawasan terhadap pengoperasian container crane di PT X Surabaya dilakukan dengan cara menyediakan orang untuk mengawasi jalannya pengoperasian container crane. Pengawasan disini dilakukan oleh pihak supervisor. Pengawasan yang dilakukan adalah mengawasi kegiatan mulai dari kapal sandar hingga selesai sandar. Sebelum dilakukan pengawasan supervisor sudah menerima lembar plan bongkar muat dari berth operation superintendent tentang berlangsungnya kegiatan mulai dari kapal sandar sampai selesai sandar.

Pengawasan ini dilakukan untuk mempermudah pengoperasian container crane sehingga tidak terjadi kecelakaan pada saat kegiatan bongkar muat. Pengawasan paling awal yang dilakukan adalah pengawasan kondisi kapal yang sandar oleh supervisor dengan panduan checklist. Pengawasan saat kapal sandar dilakukan dengan melihat kondisi dari akses, kondisi perlindungan untuk tepian, housekeeping dan penerangan.

Pengawasan terhadap kapal yang baru sandar ini selalu dilakukan oleh pihak supervisor, untuk satu kapal yang sandar dan memerlukan CC misalnya 4 CC pengawasan tetap dilakukan oleh 1 orang saja dan apabila terdapat poin-poin dalam checklist yang tidak memenuhi supervisor tetap memperbolehkan kegiatan bongkar muat dengan catatan supervisor memberitahukan kepada operator container crane tentang kondisi kapal dan tetap berhati-hati dalam mengoperasikan alatnya. Setelah kondisi kapal selesai dilakukan penilaian, supervisor melakukan pengawasan langsung di lapangan pada saat pengoperasian container crane dengan bantuan hand talky yang dilakukan tanpa panduan checklist sampai kapal selesai sandar.

Pengawasan yang dilakukan saat pengoperasian container crane dilakukan dengan mengawasi kegiatan pengoperasian container crane oleh operator, tally dan TKBM yaitu profesi yang membantu kegiatan bongkar muat. Pengawasan ini dilakukan untuk menilai apakah ada tindakan tidak aman yang dilakukan saat kegiatan bongkar muat atau kondisi yang tidak aman yang terjadi saat kegiatan bongkar muat sehingga ketika ada ketidaksesuaian saat kegiatan berlangsung bisa dilakukan pemberhentian sebelum terjadi kecelakaan. Apabila dirasa tidak terjadi masalah yang berarti pengawasan hanya dilakukan melalui HT.

\section{Maintenance Alat}

Maintenance alat yang dilakukan oleh PT X Surabaya adalah kegiatan mempertahankan kondisi dan memperbaiki alat yaitu container crane agar tetap laik dipakai dan dioperasikan. Pelaksanaan maintenance alat dilakukan oleh sub kontraktor yang dipercaya oleh PT X Surabaya yaitu PT PORTEX INDONESIA.

Maintenance alat yang dilakukan di PT X Surabaya ada beberapa macam yaitu, Maintenance berdasarkan lifetime dari alat seperti wire rope dan ganti oli. Maintenance berdasarkan hasil inspeksi, apabila kerusakan dianggap ringan maka akan dilakukan perbaikan segera namun apabila kerusakan sudah berat maka perlu dilakukan shut down operasional untuk melakukan perbaikan, Maintenance berdasarkan komplain dari pihak manajer operasional apabila container crane dianggap memiliki kekurangan; Maintenance berdasarkan checklist yaitu maintenance daily, weekly, monthly dan yearly.

Dari beberapa kegiatan maintenance diatas untuk maintenance berdasarkan lifetime alatnya sudah berjalan, namun untuk pelaksanaannya selalu mundur dari waktu lifetime alatnya karena masih menunggu acc dari manajer operasional. Maintenance berdasarkan hasil inspeksi juga sudah berjalan, untuk kerusakan ringan perbaikan bisa dilakukan saat itu juga namun untuk kerusakan berat harus menunggu acc dari manajer dan sering mengalami kendala onderdil tidak ada sehingga penggantian atau perbaikan alat sering terhambat. Maintenance berdasarkan complain dari pihak manajer operasional dilakukan bisa dilakukan secara langsung. Terakhir adalah maintenance 
berdasarkan checklist, untuk chesklist daily dan weekly bisa dilakukan dengan mudah, namun untuk maintenance berdasarkan checklist monthly dan yearly sering terhambat karena lamanya proses acc dari pihak manajer sehingga jadwalnya mundur dari yang direncanakan sebelumnya bahkan pernah perencanaan maintenance berdasarkan checklist monthly dan yearly tidak di acc.

\section{Instruksi Kerja}

Instruksi kerja pengoperasian container crane di PT X Surabaya adalah instruksi rinci terhadap tahapan-tahapan pengoperasian container crane yang harus dilakukan urut agar aktivitas berjalan aman. Instruksi kerja harus diketahui oleh operator itu sendiri maupun atasan operator tersebut.

Instruksi kerja yang ada dirumuskan oleh pihak operasional dan mengajak ahli CC dan operator superintendent, dan apabila dirasa ada yang kurang dalam dokumen instruksi kerja maka bisa direvisi. Instruksi kerja disebarluaskan kepada operator dengan memberi copy-an. Instruksi kerja singkat juga ditempel di dinding kabin $\mathrm{CC}$, tangga lift CC, dan kadang disosialisasikan saat safety talk berlangsung. Pelaksanaan instruksi kerja oleh operator kurang baik karena pada pelaksanaan operator sering mengabaikan instruksi kerja karena beranggapan bahwa ada poin-poin tertentu akan menghabiskan banyak waktu.

\section{Identifikasi Faktor Lack of Control (Inadequate Program) yang Mempengaruhi Terjadinya Kecelakaan Kerja pada Pengoperasian Container Crane di PT X Surabaya Tahun 2013-2015}

Lemahnya kontrol dari pihak manajemen termasuk di dalamnya yaitu tidak berjalannya program terkait pengoperasian container crane menjadi faktor utama tingginya kecelakaan kerja. PT X Surabaya memiliki beberapa program terkait pengoperasian container crane seperti pelatihan operator, pemeriksaan kesehatan berkala, safety talk dan pemeriksaan container crane secara umum. Program terkait pengoperasian container crane tersebut apabila terlaksana dengan baik maka akan mengurangi tingginya angka kecelakaan kerja pada pengoperasian container crane.

Ada 4 program terkait dengan pengoperasian container crane. Program tersebut dibuat untuk mengontrol kegiatan pengoperasian container crane agar nantinya tidak terjadi kecelakaan kerja. Program kedua adalah pemeriksaan kesehatan berkala bagi operator CC yang dilakukan oleh RS PHC. Program ini berjalan baik karena operator sudah mendapatkan hak pemeriksaan berkala oleh pihak PT X Surabaya dan dilakukan pada pertengahan tahun. Pelaksanaan keempat program terkait pengoperasian container crane adalah faktor utama yang mempengaruhi suatu kecelakaan kerja.

Program yang pertama adalah pelatihan atau training bagi operator yang baru berpindah dari operator RTG ke operator CC yang dilaksanakan oleh manajemen. Program ini sudah berjalan baik namun untuk pendampingan operator yang baru berpindah dari RTG ke CC yang harusnya dilakukan 3 bulan tidak terlaksana dengan baik. Superintendent dan operator sendiri mengakui bahwa pendampingan tidak dilakukan selama tiga bulan, bahkan untuk pendampingan bisa hanya dilakukan 1 minggu.

Program ketiga adalah safety talk yang dilakukan oleh supervisor. Pelaksanaan program ini sudah baik. Pelaksanaan safety talk selalu dilakukan pada awal shift. Program terakhir adalah pemeriksaan container crane secara umum sebelum melakukan pengoperasian container crane. Program terakhir ini tidak berjalan baik karena operator dan superintendent operator tidak pernah melakukan pengecekan kondisi container crane secara umum dengan panduan checklist. Operator hanya melakukan pengecekan ground, bertanya pada supervisor dan bertanya pada operator sebelumnya terhadap kondisi container crane.

Dari ke semua program tersebut ada dua program yang tidak berjalan dengan baik yaitu tentang pelatihan atau training operator dan pemeriksaan container crane secara umum oleh operator. Untuk program pemeriksaan kesehatan berkala dan pelaksanaan safety talk sudah baik dalam pelaksanaannya

\section{PEMBAHASAN}

Teori kecelakaan kerja dari Frank E. Bird dan George L. Germain menyebutkan bahwa kecelakaan kerja terjadi karena beberapa serangkaian peristiwa. Dari urutan peristiwa kecelakaan, faktor penyebab langsung terjadinya kecelakaan kerja adalah unsafe action dan unsafe condition. Kemudian naik lagi satu tingkat yaitu faktor yang menyebabkan unsafe action dan unsafe condition yaitu basic cause. Basic cause disini dibagi menjadi dua yaitu personal factor dan job factor. Pada penelitian ini personal faktor yang diteliti hanya sistem pengawasan, sistem maintenance alat dan instruksi kerja. Kemudian 
naik lagi satu tingkat yaitu faktor yang paling utama dari serangkaian kecelakaan kerja adalah lemahnya kontrol dari manajemen (lack of control) termasuk di dalamnya pelaksanaan program yang dibuat perusahaan guna mencegah terjadinya kecelakaan kerja.

Faktor di atas adalah faktor yang mempengaruhi terjadinya kecelakaan kerja pada pengoperasian container crane dan dari serangkaian penyebab kecelakaan kerja tersebut nanti akan bisa diketahui pada faktor yang mana terjadi kekurangan dalam penerapannya sehingga nantinya bisa sebagai bahan perbaikan guna mencegah terjadinya kecelakaan kerja.

Identifikasi faktor yang mempengaruhi langsung terjadinya kecelakaan adalah faktor Immediate Cause. Teori kecelakaan kerja dari Frank E. Bird dan George L. Germain menyebutkan bahwa penyebab langsung dari suatu kecelakaan kerja adalah unsafe action dan unsafe condition. Suatu kecelakaan bisa terjadi karena perilaku dari pekerja itu sendiri atau bisa terjadi karena lingkungan kerja yang memang tidak aman. Kecelakaan kerja bisa terjadi karena adanya kontak dengan sumber bahaya yang berlebihan sehingga menyebabkan suatu kecelakaan. Kontak yang dimaksud disini adalah kondisi dari alat kerja yang tidak baik atau perilaku pekerja yang tidak aman. Dari hasil penelitian disebutkan bahwa kecelakaan kerja pada pengoperasian container crane di tahun 2013-2015 paling banyak disebabkan oleh perilaku dari pekerja yang tidak aman yaitu sebanyak 178 kejadian $(76,07 \%)$ yang disebabkan oleh unsafe action dan 56 kejadian (23.93\%) yang disebabkan oleh unsafe condition (Manullang dkk, 2015).

Distribusi unsafe action dan unsafe condition yang menyebabkan kecelakaan kerja disini susah diidentifikasi karena keterbatasan data yang dimiliki perusahaan sehingga untuk unsafe action dan unsafe condition yang sering terjadi saat pengoperasian container crane didapatkan oleh peneliti dari hasil wawancara Menurut hasil wawancara unsafe action yang sering dilakukan oleh operator adalah pengoperasian alat yang tidak sesuai dengan SOP (Standar Operasional Prosedur) dikarenakan operator yang ingin cepat selesai dalam melakukan pekerjaannya dan lebih banyak dalam melakukan bongkar muat sehingga mereka bisa mendapatkan premi yang lebih besar. Pengoperasian alat tidak sesuai SOP yang sering terjadi adalah ketika operator melakukan gerakan hoist up dan hoist down mereka tidak melakukan kombinasi dengan gerakan trolley sehingga container yang diangkat terpeleset dan menabrak fasilitas kapal atau fasilitas dermaga. Penyebab kecelakaan lain yang disebabkan oleh operator adalah tidak adanya aba-aba dari TKBM saat melakukan bongkar muat dengan CC. Harusnya ketika melakukan kegiatan bongkar muat operator harus menerima aba-aba terlebih dahulu dari TKMB untuk mengetahui apakah container tersebut sudah aman atau belum untuk diangkat. Ketika TKBM belum memberikan aba-aba atau sinyal maka operator harusnya menunggu. Pada kenyataannya operator selalu tidak sabar dalam menunggu sinyal dari TKBM sehingga mereka tetap melakukan pengangkatan tanpa adanya panduan dari TKBM. Yang paling sering terjadi adalah ketika operator tetap memaksa untuk mengoperasikan alatnya tanpa adanya aba-aba dari TKBM adalah spreader rusak saat pengangkatan karena salah satu kunci container yang belum terbuka sempurna.

Untuk unsafe condition yang menjadi penyebab kecelakaan kerja pada pengoperasian container crane adalah kondisi dari seal guide kapal yang kurang baik sehingga ketika operator melakukan pengangkatan container sering menabrak container lain atau fasilitas kapal dan dermaga. Unsafe condition yang lain adalah keadaan air laut dan kondisi dari CC itu sendiri misalnya CC yang tibatiba tidak bisa melakukan gerakan hoist up/down dan kadang yang sering terjadi adalah lost break dikarenakan usia dari alat yang memang sudah tua.

Dari kedua faktor penyebab langsung di atas memang yang paling mendominasi adalah unsafe action. Hal ini sesuai dengan teori dari Frank E. Bird dan George L. Germain bahwa kecelakaan akan banyak terjadi dikarenakan perilaku pekerja itu sendiri. Maka dari itu diharapkan operator selalu berhati-hati dalam melakukan pekerjaannya dan diharapkan pula untuk selalu mematuhi prosedur aman yang sudah dibuat sehingga nantinya kecelakaan kerja dapat diminimalisir bahkan dihilangkan.

Faktor kedua dalam basic cause yang mempengaruhi kecelakaan kerja adalah Job factor. Job factor adalah penyebab kecelakaan kerja yang berasal dari pekerjaan pengoperasian container crane. Berikut adalah pembahasan job factor yang mempengaruhi terjadinya kecelakaan kerja meliputi pengawasan, maintenance alat dan instruksi kerja.

Pengawasan adalah kegiatan pemantauan aktivitas pekerja agar pekerja bekerja secara benar dan aman sehingga perusahaan akan mendapatkan dampaknya yaitu tujuan dari perusahaan tersebut 
tercapai. Pengawasan yang baik adalah yang dilakukan berkala dan sesering mungkin sehingga ketika ada kondisi yang berbahaya atau tindakan tidak aman bisa diketahui dan segera dilakukan perbaikan (Tampubolon, 2015).

Pada pengoperasian container crane pengawasan dilakukan oleh supervisor. Pengawasan awal yang dilakukan adalah mengawasi kondisi kapal dengan bantuan checklist. Pengawasan kapal dilakukan karena keadaan kapal akan berpengaruh pada saat proses bongkar muat dengan CC. Pengawasan selanjutnya adalah pengawasan saat pengoperasian $\mathrm{CC}$ yaitu saat proses bongkar muat. Pengawasan dilakukan dengan mengawasi pekerjaan tally, TKBM dan operator container crane.

Pengawasan yang dilakukan di PT X Surabaya kurang baik. Menurut hasil wawancara, pada saat dilakukan pengawasan keadaan kapal, kebanyakan supervisor tidak didampingi oleh safety supervisor, sehingga ketika ada point dalam checklist tidak sesuai supervisor tetap memperbolehkan operator untuk melakukan bongkar muat dengan himbauan operator harus tetap berhati-hati dalam melakukan bongkar muat. Pada hal ini seharusnya supervisor didampingi oleh supervisor safety pada saat melakukan pengawasan sehingga ketika keadaan kapal atau checklist ada ketidaksesuaian keputusan untuk melanjutkan dilakukannya bongkar muat bisa dilakukan segera. Supervisor safety atau safety lapangan adalah seseorang yang lebih mengetahui keamanan kapal untuk dilakukan bongkaran atau muatan dan seseorang yang memberi keputusan untuk kapal tersebut aman atau tidak dilakukan bongkar muat, jadi ketika pengawasan oleh supervisor didampingi oleh safety supervisor jika ada ketidaksesuaian pada kapal safety supervisor bisa dengan cepat memutuskan apakah kapal tersebut aman untuk dilakukan bongkar muat. Pendampingan supervisor oleh safety supervisor ini harusnya dilakukan untuk meminimalkan kerugian akibat kecelakaan yang terjadi saat proses bongkar muat.

Pengawasan yang kedua adalah pengawasan yang dilakukan oleh supervisor pada saat pengoperasian CC yaitu pada saat proses bongkar muat. Pengawasan dilakukan dengan menggunakan bantuan Hand Talky dengan mengawasi pekerjaan operator CC, tally dan TKBM. Tally dan TKBM adalah 2 profesi yang membatu operator $\mathrm{CC}$ dalam melakukan bongkar muat. Pengawasan yang dilakukan saat pengoperasian CC di PT X Surabaya juga kurang baik dalam pelaksanaannya. Hal ini dikarenakan kapal yang sedang sandar tidak hanya memerlukan satu CC untuk melakukan bongkar muat, satu kapal bisa memerlukan lebih dari satu CC tergantung waktu yang diinginkan pihak ekspedisi untuk penyelesaian bongkar muat. Jika waktu yang diinginkan untuk bongkar muat cepat maka jumlah $\mathrm{CC}$ yang digunakan juga harus banyak namun hal ini harus disesuaikan dengan kondisi lapangan.

Menurut hasil wawancara ketika ada kapal sandar, kegiatan bongkar muat biasanya memerlukan 3 sampai 4 CC untuk melakukan bongkaran atau muatan. Untuk kapal yang memerlukan lebih dari satu CC pengawasan tetap dilakukan oleh satu orang. Untuk satu kapal yang sandar pengawasan dilakukan hanya oleh satu orang dari supervisor tanpa mempedulikan berapa jumlah CC yang digunakan. Operator sendiri merasa kurang apabila jika 4 CC hanya ada 1 orang dari supervisor.

Pengawasan yang dilakukan oleh supervisor disini masih dinilai kurang baik karena seharusnya ketika ada kapal sandar dan memerlukan lebih dari satu CC untuk melakukan bongkar muat, maka penyediaan pengawas juga harus disesuaikan dengan jumlah $\mathrm{CC}$ yang digunakan. Misalnya penggunaan $4 \mathrm{CC}$ maka perlu disediakan 4 orang dari supervisor untuk mengawasi kegiatan bongkar muat. Jadi untuk satu CC terdapat satu orang dari supervisor saat melakukan pengoperasian $\mathrm{CC}$ untuk kegiatan bongkar muat. Hal ini juga dilakukan agar pengawasan bisa fokus pada satu aktivitas pengoperasian container crane sehingga ketika ada kondisi atau tindakan tidak aman akan bisa segera dicegah dan bisa mengurangi angka kecelakaan kerja.

Job factor kedua yaitu maintenance, menurut Anizar (2009), maintenance adalah kegiatan perawatan untuk menjaga kondisi dari alat dan material agar tetap layak pakai. Keadaan alat atau material yang tidak layak pakai akan menyumbangkan kecelakaan kerja karena keadaan tersebut akan menyebabkan unsafe action dan unsafe condition. Maintenance harus dijadwalkan dan dilaksanakan sesuai dengan jadwal yang telah dibuat.

Menurut hasil penelitian, maintenance yang dilakukan oleh sub kontraktor PT X Surabaya sudah baik dalam pelaksanaannya. Maintenance berdasarkan lifetime seperti penggantian oli dan wire rope sudah terlaksana sesuai jadwal. Pelaksanaan maintenance berdasarkan hasil inspeksi baik dari operator maupun pihak maintenance juga sudah baik. Maintenance berdasarkan complain dari pihak 
manajer dan berdasarkan checklist juga sudah baik dalam pelaksanaannya.

Dari semua jenis maintenance yang dilakukan oleh sub kontraktor PT X Surabaya secara keseluruhan sudah baik. Namun ada beberapa kendala yaitu dukungan dari pihak manajemen yang masih kurang. Seharusnya pihak manajemen harus cepat dalam memberi keputusan ketika pihak sub kontraktor menilai harus ada perbaikan atau penggantian perangkat yang rusak dari container crane tersebut. Kendala lainnya adalah ketika ada kegiatan maintenance dan memerlukan penggantian bagian $\mathrm{CC}$ yang rusak sering ditemukan bahwa onderdil dari CC tidak tersedia dan pihak sub kontraktor harus menunggu lama untuk memperoleh onderdil tersebut. Onderdil tersebut tidak di stok oleh sub kontraktor karena harga yang terlalu mahal dan belum tentu juga nantinya akan terpakai.

Dari kendala tersebut harusnya pihak manajemen mendukung kegiatan maintenance agar tidak terjadi suatu kondisi yang tidak aman yang nantinya menyebabkan kecelakaan kerja. Misalnya adalah penggantian wire rope, penggantian wire rope dilakukan setiap 8 bulan sekali atau setiap 8000 boxes. Ketika wire rope sudah dijadwalkan diganti maka pihak manajemen harusnya tidak mengundur waktu agar penggantian bisa dilakukan segera. Wire rope adalah bagian dari $\mathrm{CC}$ yang berpengaruh pada kekuatan alat saat pengangkatan, ketika keadaan wire rope tidak baik maka kemungkinan terjadinya kecelakaan juga akan meningkat pula. Contoh yang bisa terjadi adalah container yang terpeleset jatuh karena beban angkat wire rope yang tidak sesuai. Selain kendala dari manajemen, kendala lain seperti maintenance yang harus menunggu onderdil datang juga harus diatasi. Perusahaan bisa menstok onderdil yang sering mengalami kerusakan meskipun dalam jumlah kecil, jadi ketika diperlukan penggantian bagian dari $\mathrm{CC}$ bisa langsung diganti dan tidak sampai menyebabkan kondisi tidak aman yang berpengaruh terhadap kecelakaan kerja.

Job factor kedua yaitu instruksi kerja, instruksi kerja adalah mekanisme kerja yang mengatur jelas urutan suatu aktivitas agar pekerjaan berjalan lancar dan aman. Instruksi kerja ini dibuat untuk menjamin keselamatan dan kesehatan kerja. Instruksi kerja yang dimaksud dalam pembahasan ini adalah tentang urutan aktivitas yang harus dilakukan operator sebelum mengoperasikan container crane.

Menurut hasil penelitian, instruksi kerja pengoperasian container crane sudah ada dari awal perusahaan didirikan dan terus dilakukan pembaharuan jika dirasa kurang dalam urutan aktivitas pengoperasian container crane. Untuk pembaharuan instruksi kerja PT X Surabaya mengajak manajemen tingkat atas dan mengajak ahli CC yaitu yang dimaksud disini adalah operator superintendent untuk bersama dalam merumuskan instruksi kerja. Sebagai masukan untuk perusahaan, seharusnya pihak manajemen mengajak perwakilan operator untuk merumuskan intruksi kerja karena yang bisa merasakan ada tidaknya kekurangan dalam instruksi kerja adalah pelaku langsung kegiatan pengoperasian container crane yaitu operator, hal ini tidak sesuai dengan teori yang disebutkan oleh Ramli (2013), bahwa instruksi kerja harusnya ditinjau ulang secara berkala dengan melibat para pekerja karena pekerja yang paling berkepentingan dengan instruksi kerja tersebut.

Untuk pelaksanaan dan implementasi instruksi kerja di lapangan dinilai peneliti masih kurang baik. Seharusnya instruksi kerja dilakukan agar setiap urutan kerja yang dilakukan aman, namun ada kenyataannya operator sering mengabaikan instruksi kerja yang telah dibuat dengan alasan menghabiskan banyak waktu untuk melakukannya.

Faktor terakhir dan yang paling utama mempengaruhi terjadinya kecelakaan kerja pada pengoperasian container crane di PT X Surabaya Tahun 2013-2015 adalah faktor lack of control (inadequate program). Lack of control adalah penyebab paling utama suatu kecelakaan kerja, lack of control yang dimaksud disini adalah kegagalan dari tingkat manajemen untuk mencegah terjadinya kecelakaan kerja. Untuk melakukan pencegahan kecelakaan kerja pembenahan di tingkat manajemen harusnya dipertimbangkan untuk dilakukan. Kegagalan manajemen yang akan dibahas di sini adalah tentang kepatuhan pelaksanaan program terkait pengoperasian container crane.

PT X Surabaya memiliki beberapa program yang terkait dengan pengoperasian container crane. Program-program tersebut adalah tentang pemberian pelatihan dan pendampingan bagi operator baru, pemeriksaan kesehatan berkala, safety talk dan pemeriksaan container crane secara umum. Ketika semua program tersebut bisa terlaksana dengan baik maka faktor lain yang menjadi penyebab kecelakaan kerja akan bisa diminimalisir bahkan dihilangkan.

Menurut hasil penelitian program-program terkait pengoperasian container crane di atas sudah baik dalam pelaksanaannya namun ada juga yang tidak berjalan sama sekali. Untuk program pelatihan dan pendampingan operator baru sudah 
berjalan dengan baik namun masih ada sedikit kekurangan yaitu tidak pernah dilakukan refresh pelatihan tentang pengoperasian container crane. Refresh pelatihan di sini dimaksudkan untuk mengingatkan kembali pengetahuan operator tentang pengoperasian container crane yang aman dan benar. Untuk kekurangan yang kedua yaitu terjadi saat pendampingan operator yang baru berpindah dari RTG ke CC, pendampingan harusnya dilakukan selama 3 bulan, namun pada saat wawancara operator mengaku tidak pernah didampingi selama 3 bulan, ada yang hanya dilakukan pendampingan seminggu dan dibiarkan melakukan pengoperasian sendiri.

Program kedua adalah pemeriksaan kesehatan berkala, menurut hasil penelitian pemeriksaan berkala sudah baik dilakukan. Operator sudah mendapatkan hak pemeriksaan untuk mempertahankan kondisi kesehatan mereka agar tidak mengganggu pekerjaan mereka.

Program ketiga adalah pelaksanaan safety talk, pelaksanaan safety talk di lapangan sudah baik. Sebelum bekerja selalu dilaksanakan safety talk yang dilakukan oleh supervisor kepada para operator sebelum bekerja. Program terakhir adalah pemeriksaan container crane secara umum oleh operator. Di sini orang yang paling mengetahui ada atau tidak adanya kekurangan dari $\mathrm{CC}$ adalah operator sendiri, jadi ketika ada kekurangan dari alatnya operator bisa menunjuk tim maintenance untuk melakukan perbaikan. Program pemeriksaan container crane secara umum ini seharusnya dilakukan sebelum pengoperasian container crane pada setiap shift-nya. Pada kenyataannya pelaksanaan program ini sama sekali tidak berjalan karena operator beranggapan akan menghabiskan banyak waktu apabila harus melakukan pemeriksaan sendiri.

Dari program-program di atas, harusnya pihak manajemen mengontrol pelaksanaannya di lapangan dengan salah satu contoh yaitu memberikan reward/ punishment agar setiap pekerja selalu melaksanakan program terkait CC tersebut dengan baik. Program training dan pendampingan harusnya pihak manajemen bersungguh-sungguh berkomitmen untuk melaksanakannya.

\section{SIMPULAN}

Kecelakaan kerja pada pengoperasian container crane di PT X Surabaya adalah kecelakaan yang tergolong tinggi meskipun kecelakaan yang terjadi masih dalam kategori kecelakaan ringan. Jumlah kejadian selama tahun 2013-2015 yaitu 234 kasus kecelakaan kerja dengan nilai rata-rata frequency rate, severity rate dan incidence rate yang didapat yaitu 476,82, 0 dan 110 . Nilai severity rate yang didapat 0 dikarenakan kecelakaan yang terjadi tidak pernah sampai menimbulkan jam kerja hilang lebih dari $2 \times 24$ jam (LTI).

Dari identifikasi kasus kecelakaan kerja di atas, didapatkan beberapa faktor yang mempengaruhi kecelakaan kerja pada pengoperasian container crane. Penyebab langsung dari kecelakaan kerja sebagian besar disebabkan oleh unsafe action dari operator yaitu sebanyak 178 kecelakaan $(76,07 \%)$ dan sebanyak 56 kejadian. Disebabkan unsafe condition $(23,93 \%)$. Faktor lain yang mempengaruhi terjadinya kecelakaan kerja adalah sistem pengawasan, instruksi kerja, maintenance alat dan beberapa program terkait pengoperasian container crane yang tidak berjalan dengan baik seperti pengecekan alat sebelum bekerja.

Saran yang bisa diberikan adalah perlu dipertimbangkan untuk melakukan rekruitmen tenaga kerja untuk pengawasan atau pengaturan tugas dengan baik, agar kegiatan pengawasan pada pengoperasi container crane berjalan maksimal sehingga nantinya akan menurunkan angka kecelakaan. Implementasi instruksi kerja harusnya dilakukan dengan baik untuk poinpoin yang penting, sosialisasi berkala diperlukan untuk mengingatkan operator akan instruksi kerja. Sosialisasi bisa disampaikan saat safety talk atau bisa dengan menempel instruksi kerja singkat di kabin operator atau tempat yang mudah dilihat. Kegiatan maintenance alat harus lebih ditingkatkan terutama dukungan dari pihak manajemen agar mendukung penuh kegiatan yang sudah direncanakan oleh tim maintenance. Pemberian refresh pelatihan minimal 2 tahun sekali bagi operator untuk merefresh pengetahuan operator tentang pengoperasian container crane dan yang terakhir implementasi pemeriksaan container crane sebelum bekerja sebaiknya perlu ditingkatkan untuk menghindari unsafe condition yang nantinya menyebabkan kecelakaan.

\section{DAFTAR PUSTAKA}

Anizar. 2009. Teknik Keselamatan dan Kesehatan Kerja di Industri. Yogyakarta: Graha Ilmu.

Bird, F.E and Germain. G.L, 1992. Safety, Health, Environmental, and Quality Management Second 
Edition. Georgia: International Risk Control America, Inc.

Fhadilla, A.R. 2016. Analisis Faktor Penyebab Kecelakaan Kerja pada Pengoperasian Container Crane di PT X Surabaya. Skripsi. FKM, Universitas Airlangga. Surabaya.

Manullang, H., Kusmindari, D., Pasmawati, Y. 2015. Analisis Penyebab Kecelakaan Kerja dengan Menggunakan Metode Fault Tree Analysis. Tersedia di: http://digilib.binadarma.ac.id.pdf/ [diakses tanggal 31 Januari 2017].

McKinnon, R.C. 2000. Cause, Effect, and Control of Accidental Loss with Accident Investigation Kit. Washington D.C: Lewis Publishers.
Ramli, S. 2013. Smart Safety, Panduan Penerapan SMK3 Yang Efektif. Jakarta: Dian Rakyat.

Tampubolon, L.J. 2015. Efektivitas Pengawasan Keselamatan dan Kesehatan oleh Dinas Sosial dan Tenaga Kerja Kabupaten Sidoarjo sebagai Upaya Mewujudkan Budaya K3. Jurnal Kebijakan dan Manajemen Publik, volume 3 (nomor 3): 36-39.

Trivitas, S.P. 2016. Analisis Eksistensi Perusahaan Bongkar Muat dalam Konteks Layanan Transportasi Laut - Studi Kasus: Tanjung Perak. Jurnal Teknik: 1. 